\title{
Revisiting the Maturation of Medial Temporal Lobe Memory Functions in Primates
}

\author{
Maria C. Alvarado ${ }^{1}$ and Jocelyne Bachevalier \\ University of Texas Health Science Center, Houston, Texas 77001 USA
}

\begin{abstract}
In a review of the literature on the development of the medial temporal lobe region in humans, monkeys, and rodents, Bachevalier and Beauregard indicated that in primates, memory functions subserved by this neural system emerge early in life and increment gradually with further postnatal maturation. Furthermore, they stated that the late-developing memory functions of normal neonates was more likely owing to the slow maturation of the association areas of the cortex than to the slow maturation of the hippocampal formation. This conclusion was based on the limited knowledge concerning the development of hippocampal-dependent memory functions and the maturational events in the medial temporal lobe of monkeys. Over the last decade, however, more information has accumulated about the structural, functional, and behavioral changes occurring throughout ontogeny in monkeys that suggest a refinement of this view. Whereas there is still much to be discovered, we thought it timely to put into perspective the latest findings in hope of shedding light on memory development in general, and particularly, on the role of medial temporal lobe structures in infant and adult memory. [Note: Hippocampal formation refers to the hippocampus proper (Ammon's fields), dentate gyrus, and subicular complex. Hippocampal region refers to the hippocampal formation and the adjacent entorhinal, perirhinal, and parahippocampal cortex.]
\end{abstract}

It is generally accepted that memory is not a unitary process, but rather consists of multiple systems (for review, see Squire 1994), only one of which depends critically upon the hippocampal formation. The dissociation between these memory systems has received further support from developmental studies of memory in which it has been shown that memory processes that are sensitive to hippocampal dysfunction in adults are late developing in infants. Such findings have been particularly well documented in rodents. Because neurogenesis in the rodent dentate gyrus is almost entirely postnatal, the onset of particular behavioral events can be readily compared to maturational changes in the hippocampal formation (Altman et al. 1973; Douglas 1975). In particular, these behavioral functions emerge between ages 20 and $25 \mathrm{~d}$, just at the end of neurogenesis and synaptogenesis in the dentate gyrus (Altman and Das 1965; Altman and Bayer 1975; Bayer 1980). For example, the ability to navigate to a hidden platform in a water maze (Rudy et al. 1987) or perform a delayed alternation task (Freeman and Stanton 1991) first appears at this age and is impaired in adults with damage to the hippocampal formation (Morris et al. 1982). This tight link between maturational events within the rodent hippocampal formation and associated structures and emergence of memory abilities has encouraged the extension of these comparisons to other species, including human and non-human primates.

${ }^{1}$ Corresponding author.

E-MAIL maria.c.alvarado@uth.tmc.edu ; FAX (713) 500-0621. Article and publication are at www.learnmem.org/cgi/doi/ $10.1101 / \mathrm{lm} .35100$.
One striking difference between rodent and primate species is that the neurogenesis of the hippocampus proper and dentate gyrus in monkeys and humans is almost entirely prenatal (Rakic and Nowakowski 1981; Eckenhoff and Rakic 1988). Thus, one might expect to find that hippocampally mediated memory functions should appear comparatively early in primate development. Indeed, some behavioral evidence suggests that the hippocampal-dependent memory system is available as early as the first months or weeks of life in monkeys (Gunderson and Sackett 1984; Bachevalier et al. 1993) as in humans (Diamond 1990; Pascalis and de Schonen 1994). Thus, monkeys show lasting recognition memory in the first month of life, and humans in the first 3-6 mo. This ability is impaired in monkeys and humans with damaged hippocampal regions. Although these data led to the conclusion that the hippocampal formation is mature relatively soon after birth in primates (Diamond 1990; Bachevalier and Beauregard 1993), there is equally compelling behavioral and anatomical evidence to suggest that maturation of the hippocampal-dependent memory system is a protracted process that continues for the first 30 mo in the monkey (Harlow 1959; Bachevalier and Mishkin 1984), and the first 5-7 yr in the human (Rudy et al. 1993; Overman et al. 1996). Conversely, there is mounting evidence that certain hippocampal functions in rodents are available before the completion of neurogenesis in the dentate gyrus (Lobaugh et al. 1985; Saperstein et al. 1989). Thus, it appears that some hippocampal-dependent functions emerge at a time when the hippocampal formation has not reached complete maturation, whereas other

LEARNING \& MEMORY 7:244-256 @ 2000 by Cold Spring Harbor Laboratory Press ISSN1072-0502/00 \$5.00

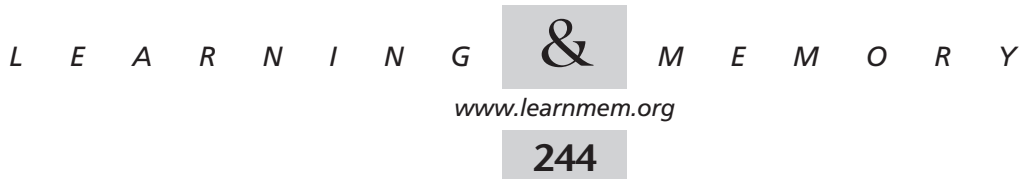


functions require a fully developed hippocampal formation. These unexpected results prompted us to re-examine this issue.

One difficulty with earlier studies that link maturation of memory processes with maturation of the hippocampal formation is that they usually take into account developmental events occurring within this structure, but often fail to take into account developmental changes in those structures that have interconnections with the hippocampal formation. It is important to bear in mind that delayed maturation in any one structure within the neural network supporting visual memory could affect the flow of information within the network and result in altered performance. Another potential difficulty is that the neural circuit supporting a specific memory process in the adults may not necessarily be that used by the infants to support the same function. Consequently, linking the emergence of a function to the maturation of a specific brain structure may not be as straightforward as previously believed. In light of the foregoing considerations, we intend to focus this review not only on the development of the hippocampus formation, but also on what is known about the development of related medial temporal cortical structures and their contributions to the maturation of memory functions in non-human primates.

However, there are still many gaps in our knowledge of specific developmental events in monkeys. We will therefore occasionally include data from rodents or humans because there is strong evidence to suggest that the ontogenetic progression of structural and cognitive function is parallel across species, even though timing relative to birth may differ. We first show that the hippocampal formation may have numerous functions with regard to memory and that these may be reflected not only in changes in its local circuitry, but also in changes in the pattern of its extrinsic connections. Second, the pattern of development of these connections suggests that the functional maturation of the hippocampal formation is a prolonged, continual process, with some circuitry and supported functions present early in infancy and others coming on line throughout the first years of life. Finally, we argue that the study of hippocampal development may provide valuable insights into the role of this structure in learning and memory in the adult and may suggest directions for future research.

\section{Development of Medial Temporal Lobe Memory}

A number of paradigms have been used to assess the development of medial temporal lobe (MTL) memory functions in primates. As described below, two involve recognition memory tasks and the other involves relational memory tasks. Performance on these tasks is often differentially sensitive to damage to specific structures in the medial temporal lobe, and adultlike proficiency on these tasks shows a range of maturational onset with adult performance emerging quite early for some tasks, and much later for others. We will discuss each behavioral paradigm in the approximate order in which adult proficiency emerges in monkeys.

\section{Recognition Memory Tasks}

Preferential Looking Task

Perhaps the earliest MTL-dependent memory function present in primates is recognition memory. Using the monkey's natural tendency to prefer novel stimuli as an index of memory, recognition memory has been showed in the first 2 wk of life in monkeys (Gunderson and Sackett 1984; Bachevalier et al. 1993) and in the first few days in humans (Pascalis and de Schonen 1994). Recognition memory at these early ages has typically been tested in the preferentiallooking (PL) paradigm (also known as the visual-paired comparison paradigm) (Fantz 1964; Fagan 1970). In this task, the subject is exposed to a visual stimulus during a familiarization period, followed by a delay, during which no stimuli are present. In the comparison period, the familiar stimulus is presented side by side with a novel stimulus, during which the subject's eye movements are recorded. Recognition is inferred from the subject's tendency to prefer, and thus fixate longer to, the novel stimulus. Memory can be further taxed by varying the interval during the presentation of the sample and novel stimuli. Using this paradigm (Fig. 1A), Bachevalier and colleagues (1993) showed that monkeys as young as $4 \mathrm{wk}$ old were able to show novelty preference after a $10 \mathrm{sec}$ delay (longest tested). Using longer retention periods, Gunderson and Swartz (1985) reported that infant monkeys could recognize visual stimuli after a 24-h delay as early as the age of 1 mo.

Performance on PL is highly susceptible to medial temporal lobe damage in adult monkeys (Table 1). For example, ablation of area TE in monkeys completely abolishes novelty preference (Bachevalier 1990; Buffalo et al. 1999). Perirhinal cortex lesions impair recognition memory for objects at delays of $10 \mathrm{sec}$ or longer (Clark et al. 1996; S. Nemanic, M.C. Alvarado, and J. Bachevalier, unpubl. obs.), whereas damage to area TH/TF disrupted recognition memory only after $30 \mathrm{sec}$ (Nemanic et al. 2000). Finally, damage to the hippocampal formation yields delay-dependent impairments that vary with the extent and method of the lesion and that appear between $10 \mathrm{sec}$ (Zola et al. 2000) and 30 sec (Pascalis and Bachevalier 1999; Nemanic et al. 1999). Because performance on this task shows such high dependence on several medial temporal lobe structures and because it appears so early in life, this suggests that one or more of these structures may functionally be able to support recognition memory in infants. In fact, preference for novelty is abolished by extensive neonatal damage to the MTL (amygdala, hippocampus, and adjacent cortex) in 1-mo-old monkeys (Bachevalier et al. 1993) or by limited neonatal damage to the hippocampal formation and para-

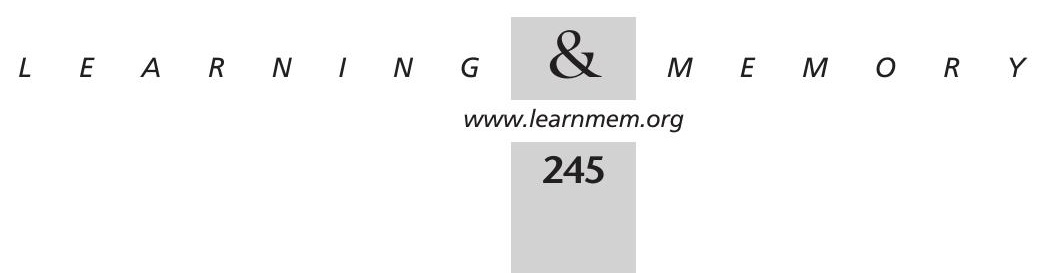


A

\section{Preferential Looking}

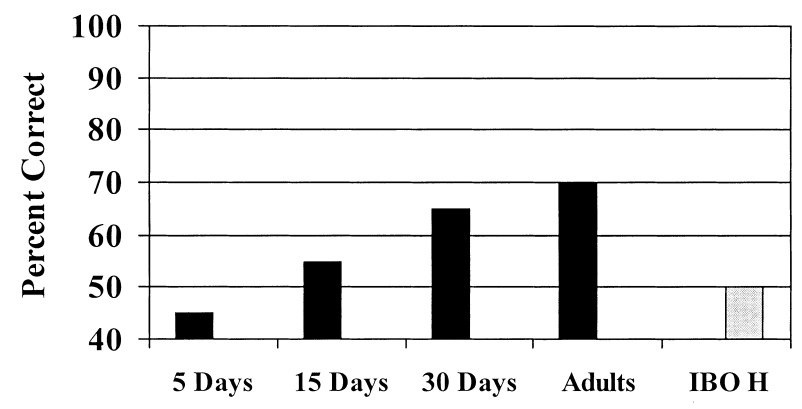

B

\section{Delayed Non-Matching-to-Sample}

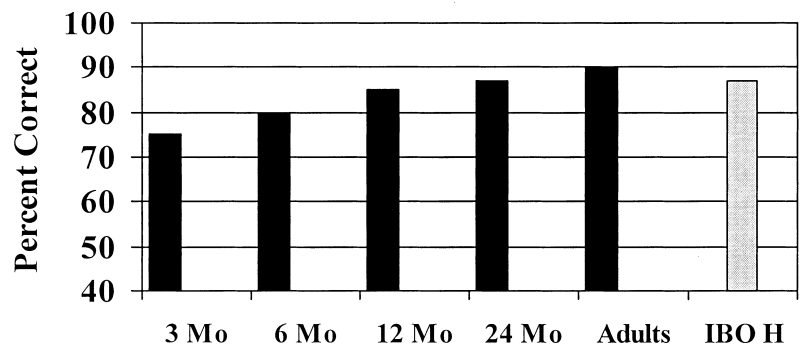

Figure 1 Development of Recognition Memory. (A) Performance on Preferential Looking as a function of age (solid bars) (Bachevalier 1990). IBO H (shaded bar) refers to performance of three adults with neurotoxic lesions of the hippocampal formation (adapted from Nemanic et al. 1998). (B) Performance on DNMS as a function of age (solid bars) (adapted from Bachevalier 1990). IBO H (shaded bar) refers to performance of adults with neurotoxic damage to the hippocampal formation (adapted from Nemanic et al. 1998). Adults were $4 \mathrm{yr}$ or older.

hippocampal gyrus in adults (Pascalis and Bachevalier 1999). Although these findings support the idea that some MTL structures are operating early in life to support recognition memory, they do not indicate which of these structures might be functional at this early age.

\section{Delayed Non-Matching-to-Sample}

Despite the early emergence of preference for novelty, the ability to use novelty as a guide for choice behavior develops much later as, for example, in the delayed non-matching-to-sample task (DNMS). The DNMS task measures visual recognition memory but it also requires problem-solving capabilities. In this task, the monkey is presented with a sample object that covers a baited food well. The monkey displaces the object to retrieve the reward. A short delay period follows, during which the monkey cannot see the testing tray. During the choice test, the sample and a novel object are presented over the lateral wells of the test tray, but only the well under the novel object is baited. Using new stimuli for each trial, the subject must learn to pick the item not previously seen. Memory capacity can be taxed further by increasing the retention delay, or by increasing the number of items to be remembered. Bachevalier and Mishkin (1984) showed that 3-mo-old monkeys could not master DNMS even at short delays of $10 \mathrm{sec}$, and yet, at the same age, infants show long-lasting recognition as measured by PL (see above). Indeed, adult-like performance on the DNMS task (Figs. 1B,2) did not emerge until age1 to $2 \mathrm{yr}$ (Bachevalier 1990; Mahut and Killiany 1990). Human infants show a similar protracted development of mastery of DNMS, not reaching adult proficiency levels before age $2 \mathrm{yr}$ (Diamond 1990; Overman 1990). Furthermore, the ability to remember across increasingly longer delays also improves with age (Diamond 1990).

Acquisition and performance on DNMS is highly susceptible to medial temporal lobe damage. As in PL, both acquisition of DNMS and performance across delays are severely impaired by damage to area TE (Bachevalier and Mishkin 1994), as well as to the entorhinal and perirhinal cortices, or to the perirhinal cortex alone (Horel et al. 1987; George et al. 1989; Murray 1992; Meunier et al. 1993; Suzuki et al. 1993; Zola-Morgan et al. 1989, 1993; Eacott et al. 1994; Alvarez et al. 1995). Damage to the parahippocampal areas TH and TF slightly retards acquisition of DNMS and affects memory for objects only at the longest delays of 10 min (Nemanic et al. 2000), whereas the same damage severely impairs performance on a spatial version of the task (M.C. Alvarado and J. Bachevalier, unpubl.). Finally, in contrast to the severe recognition memory impairment on PL after hippocampal ablation (compare Fig. 1A,B), all studies show only mild impairment on DNMS performance; some have argued at delays as short as $15 \mathrm{sec}$ (Beason-Held et al. 1999; Zola et al. 2000), whereas others claim not before 10 min or beyond (for review, see Mishkin and Murray 1996; Bachevalier et al. 1999, Nemanic et al. 1999). Thus, it appears that for DNMS, as for PL, the MTL cortical areas play a key role in both acquisition and performance of the task.

Given the similarity of the two recognition tasks (PL and DNMS) and the importance of many of the medial temporal lobe structures for performance on both tasks, one could wonder why their developmental timetables are so different. Several studies have already shown that the differences could not be accounted for by differing abilities to detect the novel stimulus (Overman et al. 1993), nor can they reflect simple immaturity in reaching ability (Diamond 1990; Overman et al. 1993) or the inability to retain the sensory information for long periods (Gunderson and Swartz 1985). Rather, the differences between the development of the two tasks appear to be related to an inability to associate the reinforcer with the abstract quality of novelty

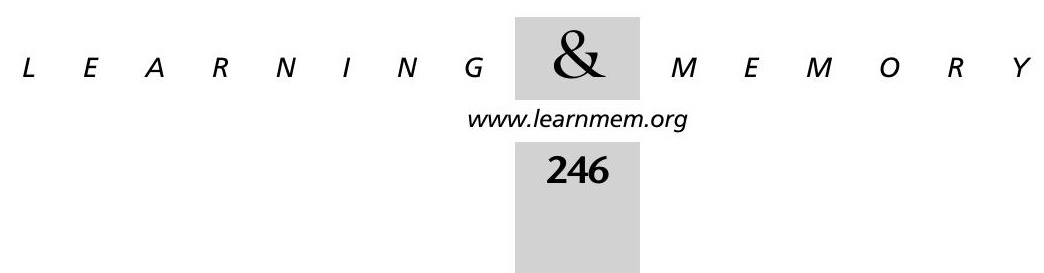


Table 1. Lesions Affecting Performance on Preferential Looking

\begin{tabular}{lcl}
\hline Lesion & Impaired at (sec) & \multicolumn{1}{c}{ Study } \\
\hline Hippocampal region (aspiration) & 30 & Pascalis \& Bachevalier 1999 \\
Hippocampal formation (radiofrequency) & 60 & Zola et al. 2000 \\
Hippocampal formation (ibotenic acid) & 10 & Zola et al. 2000 \\
Hippocampal formation (ibotenic acid) & 30 & Nemanic et al. 1998 \\
Perirhinal cortex & 10 & Clark et al. 1997 \\
Area TE & 1 & Buffalo et al. 1998 \\
Area TH/TF & 30 & Nemanic et al. 2000 \\
\hline
\end{tabular}

6-mo and 1-yr-old infant monkeys were impaired relative to adults on performance of such a task. That is, they made more errors than normal adults in acquiring the discrimination, and were impaired relative to adults when required to show knowledge of stimulusstimulus relations by choosing $\mathrm{B}$ over C when object A was present, and the converse when object D

in DNMS trials (Bachevalier 1990; Overman et al. 1993; Diamond 1995; Diamond et al. 1999). Therefore, we must conclude that, unlike PL, the DNMS task requires cognitive abilities beyond simple recognition. These abilities must depend upon neuronal substrates within and outside of the medial temporal lobe that mature throughout the first year of life in the monkey. Possible candidates include the ventral portions of the prefrontal cortex (Goldman-Rakic 1987; Meunier et al. 1997; Málková et al., in press) and the inferior temporal cortical areas (Bachevalier et al. 1991; Rodman 1994).

\section{Relational Memory Tasks}

\section{Biconditional Discrimination}

This task measures the ability to acquire stimulus-stimulus relations. Subjects are trained to discriminate four stimulus pairs: $\mathrm{AB}, \mathrm{AC}, \mathrm{CD}$, and $\mathrm{BD}$, in which $\mathrm{AB}$ and $\mathrm{CD}$ are rewarded pairs and $\mathrm{AC}$ and $\mathrm{BD}$ are unrewarded pairs (e.g., Saunders and Weiskrantz 1989). In other words, A and D are conditional cues whose presence determines whether B or C is correct. Killiany and Mahut (1990) have shown that was present. In addition, 1-yr-old monkeys with damage to the hippocampal region (i.e., hippocampal formation and parahippocampal cortical areas TH and TF) were similarly impaired on this task relative to performance of both 1-yr-old normal infants and normal adults. These findings suggest that relational memory processes are available but not adult-like at the age of $1 \mathrm{yr}$ (Killiany and Mahut 1990).

\section{Spatial Learning}

Spatial memory tasks require the ability to select the appropriate navigational trajectory based on a specific arrangement of environmental cues. In rodents, memory abilities requiring the use of spatial relations develop at the age of $\sim 21 \mathrm{~d}$ (Rudy, et al. 1987), and coincide with the end of the period of neurogenesis in the dentate gyrus (Bayer and Altman 1974). Although the development of spatial memory has not been systematically studied in infant monkeys, neonatal damage to the hippocampal region impairs spatial memory when the operated monkeys are tested as adults on a spatial version of the DNMS task (Mahut and Moss 1986; Málková et al. 1995; Alvarado et al. 1995). Using tests adapted from the rodent literature, Overman and colleagues (1996) have recently shown that human children can perform animal tests of spatial memory at the age of $\sim 5 \mathrm{yr}$, but do not show adultlike proficiency until the age of $\sim 8 \mathrm{yr}$. If the developmental pattern in monkeys follows the same pattern as that in rodents and humans, then we could speculate that proficient use of spatial relations in monkeys should appear at the end of the first year but may improve over the second year of life.

\section{Transverse Patterning}

Successful performance on the transverse patterning problem (Spence 1952) also requires rela-

Figure 2 Acquisition of DNMS as a function of age (adapted from Bachevalier 1990).

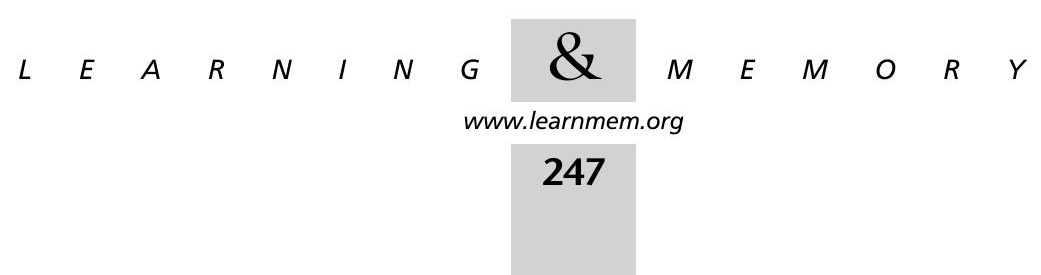


tional memory abilities and is also late-developing, emerging at the age of $\sim 1 \mathrm{yr}$ in monkeys (Málková et al. 1999) with adult like proficiency appearing between 2 and $3 \mathrm{yr}$ (Fig. 3). In this task, subjects learn three discrimination problems that are presented concurrently: $\mathrm{A}+$ versus $\mathrm{B}-, \mathrm{B}+$ versus $\mathrm{C}-$, and $\mathrm{C}+$ versus $\mathrm{A}-$. Successful performance on the task requires the subject to ignore absolute reward contingencies ( $50 \%$ for each stimulus), and instead, attend to the relationships between stimuli (Spence 1952; Alvarado and Rudy 1992). The ability to learn the transverse patterning discriminations is similarly developmentally delayed in humans, who are unable to solve the task until the age of $\sim 5$ yr (Rudy et al. 1993), and in rodents, who begin to solve the task at the age of $\sim 30 \mathrm{~d}$ (J.W. Rudy and M.C. Alvarado, unpubl.), well after spatial learning abilities appear (2125 d).

Evidence that this developmental delay reflects maturational processes within the medial temporal lobe is provided by studies in which performance on this task is severely impaired by hippocampal lesions. For example, performance was impaired in adult monkeys with either neonatal damage to the hippocampocampal region (Alvarado et al. 1995), or neurotoxic damage to the hippocampal formation sustained in adulthood (see Fig. 3; Alvarado et al. 1998), in amnesic humans with hippocampal or temporal lobe damage (Rickard and Grafman 1998; Reed and Squire 1999), and in rats with neurotoxic damage to the hippocampal formation (Alvarado and Rudy 1995a,b).

Oddity Task

Further examples of delayed development of relational memory abilities are provided by the oddity task. In this task, the subject is shown an array of three stimuli, two of which are identical. The subject is required to pick the unique (or odd) stimulus to obtain a reward (e.g., A -, A -, $\mathrm{B}+$ ). Thus, there is nothing about the absolute properties of the stimuli to direct choice toward any of the stimuli.

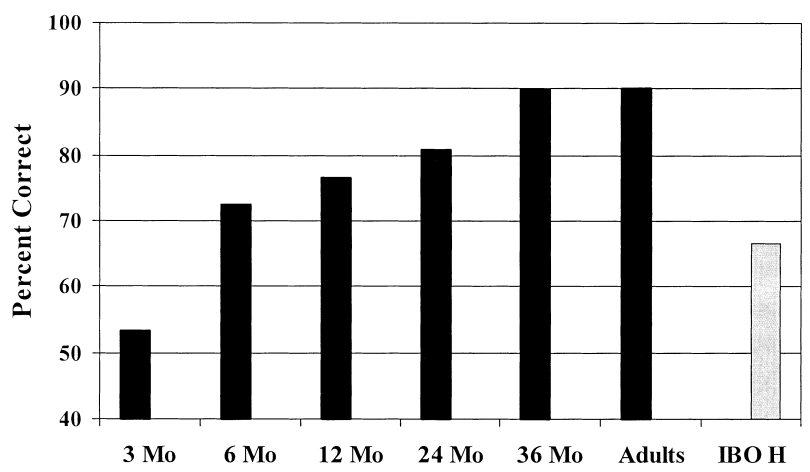

Figure 3 Performance on Transverse Patterning as a function of age (solid bars). (adapted from Málková et al. 1999). IBO H (shaded bar) to performance of three adults with neurotoxic lesions of the hippocampal formation (adapted from Alvarado et al. 1998). Adults were $4 \mathrm{yr}$ and older.
Rather, the value of each stimulus directly depends on which other stimuli are present. Harlow trained infant monkeys on this task and found that they did not attain adult-like performance until age 3 or 4 yr (Harlow 1959). Similarly, human children have difficulty solving the task until age 5 or $6 \mathrm{yr}$ (Gollin and Schadler 1972; Overman et al. 1996). It is not known whether hippocampal damage affects performance on this task, although damage to inferior temporal cortex impairs postoperative relearning of the oddity principle (Iversen and Humphrey 1971).

\section{Summary}

From the previous discussion, it should be clear that the memory abilities supported by the medial temporal lobe structures do not show a single pattern of development. Some processes (e.g., recognition memory) are present in the first months of life, but mature over the first year, whereas tasks requiring greater cognitive demands (e.g., relational memory) emerge later and mature over many years. Yet, performance on each of these tasks shows sensitivity to hippocampal damage. Thus, the development of adultlike proficiency on behavioral tasks sensitive to medial temporal lobe dysfunction is a continual, rather than a stepwise process. By extension, one might expect the neural substrates of these memory abilities to show a similar developmental continuum. Whether this functional development reflects gradual maturation of either the hippocampus proper, connections within and between MTL structures, or maturation of extrinsic connections will be discussed below. However, before doing so, it is useful to briefly review what is known about the flow of information within the medial temporal lobe. Because all behavioral tasks described above test visual memory, we will focus on the visual memory circuit within the medial temporal lobe.

\section{Visual Memory Circuit}

A number of recent anatomical studies have contributed significantly to our understanding of the interconnectivity of medial temporal areas and the hippocampal formation in the adult primate brain (Insausti et al. 1987; Witter et al. 1989; Suzuki and Amaral 1994a,b; Suzuki 1996). The flow of information through the MTL provides an increasing convergence of sensory information that allows for processing of greater complexity. Further, the cortical areas through which information is passed to the hippocampal formation are association areas, and recent research suggests that each makes its own unique contribution to visual memory processes. Thus, it is important to determine what contribution, if any, they may make to memory early in development, and whether this contribution is independent of hippocampal function.

In adult primates, the visual information flows into the temporal lobe via two segregated pathways that provide qualitatively different visual information. Information about 
object and facial identity flows through the occipito-temporal pathway, or ventral stream, that begins in the striate cortex (area V1) and proceeds along the occipito-temporal visual pathway through $\mathrm{V} 2, \mathrm{~V} 3$, and V4 to the areas TEO and TE of the inferior temporal cortex (Desimone and Ungerleider 1989). Object representation increases in complexity along this pathway and is completely achieved in area TE. Area TE, in turn, projects heavily to the perirhinal cortex (areas 35 and 36), which also receives substantial input from the insular cortex, the orbitofrontal cortex, and the parahippocampal gyrus (Van Hoesen and Pandya 1975; Webster et al. 1991; Suzuki and Amaral 1994b). Cells in these cortical areas respond selectively to object features, such as size, shape, etc. In addition, response properties of TE neurons show decremental firing with repeated presentations of a given stimulus. This change in firing pattern provides a means of novelty, familiarity, or recency detection which can last as long as $24 \mathrm{~h}$, but which is disruptable by the presentation of more than two intervening stimuli (Baylis et al. 1987; Desimone 1992; Rodman 1994; Xiang and Brown 1998). Thus, neurons in TE may be able to support a limited form of recognition memory. Neurons in the perirhinal cortex, like those in area TE, show response decrements with repeated presentations of stimuli (Riches et al. 1991; Fahy et al. 1993; Miller et al. 1993), distinguishing novel from familiar stimuli for delays as long as $24 \mathrm{~h}$ (Xiang and Brown 1998). These response properties, however, last longer on average than those in TE, can span the presentation of 140 intervening stimuli (Brown 1996), and are enhanced when a stimulus matches a behaviorally relevant sample (Miller and Desimone 1994). Thus, in addition to indicating whether a stimulus is novel or recent, perirhinal cortex could support a labile but longer lasting form of recognition memory for a sample stimulus that is held in mind. The perirhinal cortex also provides visual inputs to the ventral portions of the prefrontal cortex and these two cortical areas have been shown to be essential for object memory (Van Hoesen et al. 1975; Bachevalier and Mishkin 1986; Kowalska et al. 1991; Meunier et al. 1997).

The second visual pathway, which primarily provides information about spatial location of objects, flows from striate cortex along the occipito-parietal pathway, or dorsal stream, to the inferior parietal cortex (Ungerleider and Mishkin 1982), reaching the temporal lobe via projections from posterior parietal cortex to area TH/TF of the parahippocampal gyrus. The parahippocampal gyrus also receives input from V4 and areas TEO and TE, and is reciprocally connected with the dorsolateral prefrontal cortex (Goldman-Rakic et al. 1984; Goldman-Rakic 1987). Neurons in this area have been shown to respond to spatial view and head direction (Robertson et al. 1999) and have place fields (Matsumura et al. 1999). Furthermore, neuroimaging studies suggest that the human parahippocampal region is activated during spatial learning (Aguirre et al. 1996). Thus, the parahippocampal cortex appears to be involved more in stimulus location than in stimulus selectivity.

Both the perirhinal and parahippocampal cortices project heavily to the entorhinal cortex (area 28), which in turn provides the major input to the hippocampal formation. Electrophysiological studies have shown that hippocampal responses are much less tied to stimulus identity than MTL cortical neurons. For example, hippocampal neurons respond during delays (Colombo and Gross 1994; Colombo et al. 1998), changes in spatial views (Rolls et al. 1997), and when a match or a mismatch is detected, thus providing a means of choice behavior (Riches et al. 1991; Hampson et al. 1993; Deadwyler et al. 1996; Wood et al. 1999). Therefore, the hippocampus is involved during recognition memory tasks, particularly during long delays and when the location of the subject or the item determines choice behavior. Responses of hippocampal neurons in relational tasks, other than spatial memory tasks, have not been investigated.

Before reviewing our knowledge of the maturation of temporal cortical areas and hippocampal formation in monkeys and discussing its relevance for the development of visual memory in monkeys, one additional point regarding the flow of inputs within the hippocampal formation needs to be addressed. The traditional view stipulates that highly processed cortical input passes, via the perforant path, from layer II of the entorhinal cortex to the dentate gyrus; via the mossy fibers, from the dentate to CA3; via Schaffer collaterals, from CA3 to CA1 fields; and finally, from CA1 to the subiculum and out to cortical and subcortical structures. However, recent work has increased our appreciation for the nature of connections within the hippocampal formation and with its cortical targets along the transverse and longitudinal axes. The findings suggest a heterogeneity of functions for this structure in that there are several segregated cortico-hippocampal loops, which may play different functional roles in addition to a potential functional differentiation along the septo-temporal axis (Yeckel and Berger 1990; Witter and Amaral 1991; Blatt and Rosene 1998; Moser and Moser 1998).

First, along the transverse axis, there is monosynaptic modulation of CA1 and subiculum originating in layer III of the entorhinal cortex, thus bypassing the dentate gyrus (Witter and Amaral 1991). Evidence for the functionality of this direct pathway in memory tasks was recently provided by Goldman-Rakic and colleagues. In a 2-DG analysis of hippocampal activity while adult monkeys were performing a DNMS task, they showed that performance of this task activates CA1, subiculum and entorhinal cortex, but not dentate gyrus or CA3 (Sybirska et al. 2000).

Second, information coming from the entorhinal cortex is integrated longitudinally along the septo-temporal axis. For example, Colombo and colleagues (1998) showed that in monkeys, neurons in the posterior portion of the

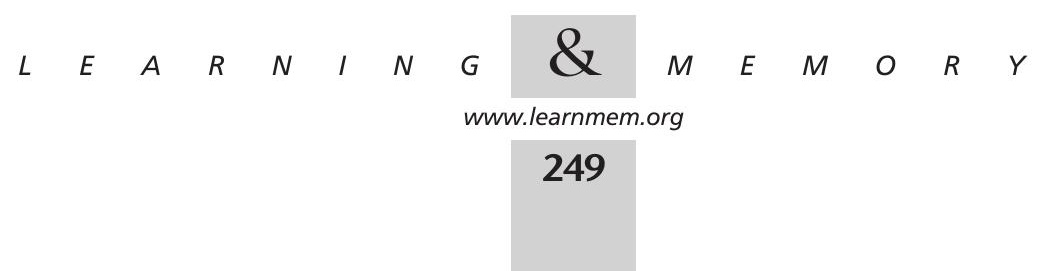


hippocampal formation responded more to delays during spatial tasks, whereas neurons distributed throughout the hippocampal formation responded to delays during nonspatial memory tasks. Thus, the anatomical and electrophysiological evidence does not support the idea of a lamellar organization of the hippocampal formation.

Finally, from the CA fields, information leaves the hippocampal proper via several routes. The subicular complex which projects back to the entorhinal cortex and the fornix, which conveys visual information to subcortical structures. In addition, the CA1 field projects in a highly topographic manner to the entorhinal, perirhinal, and parahippocampal cortices, suggesting further segregation of information and a potentially unique role for this hippocampal field in mnemonic functions (Blatt and Rosene 1998).

Altogether, the previous discussion indicates that there are modules within a given area of the visual streams that could individually support certain aspects of memory function. This idea is particularly important with respect to hippocampal development. For example, as discussed below, at those ages when the trisynaptic circuit is not functional, the CA1-entorhinal circuit may nevertheless be operational and could support a limited subset of behaviors. This idea also has implications for the adult, in that these modules may support the same behaviors in the mature animal.

\section{Development of Medial Temporal Lobe Structures}

Although there is still controversy as to the contribution of individual medial temporal lobe structures to learning and memory tasks, immaturity in any or all of these structures could influence visual memory processes during ontogeny. Therefore, in this paper we describe what is known about the development of each area to determine which structures are available to support memory at different developmental ages. We focus on the hippocampal formation, the entorhinal cortex, and the inferior temporal cortex, because most information has been gathered on these structures both in terms of functional development and in terms of behavioral functions. Considerably less information is available on the development of the perirhinal cortex or the parahippocampal gyrus (areas TH and TF), but some behavioral data may shed light on the functional development of these areas as well.

\section{Inferior Temporal Cortical Areas TE and TEO}

Anatomical studies indicate that both TE and TEO have established feedforward and feedback connections by the first week of life in monkeys. However, the pattern of connections in the infant has striking differences from the pattern in the adult. In particular, TEO has strong connections with the lateral basal nucleus of the amygdala and area TF that do not persist into adulthood. Furthermore, connections of area TE with the perirhinal cortex are more widespread in infants than in adults (Webster et al. 1991, 1995). These transient projections retract and the adult pattern of connections is established between ages 2 and 6 mo (M. Webster, J. Bachevalier, and L. Ungerleider, unpubl.). Additional evidence of the functional development of these areas comes from lesion and electrophysiological studies.

Damage to area TE produces profound impairments on DNMS in adult animals but yields a mild impairment when the damage is sustained in infancy (Bachevalier and Mishkin 1994). Furthermore, such damage results in the retention of the infant pattern of normally transient projections from TEO (Webster et al. 1995). These results suggest that area TEO is functional at birth whereas area TE is, at best, functionally immature.

Electrophysiological evidence also suggests that TE is immature at birth. Whereas cells in area TE show adult-like stimulus selectivity in awake, behaving animals by the end of the first month, the strength of both driven and spontaneous responses in infants was weaker than those of the adults and was almost entirely suppressed in anesthetized infants younger than the age of 4 mo (Rodman et al. 1993). Furthermore, metabolic studies have shown that cerebral glucose utilization in this region peaks at the age of 4 mo in infant monkeys and reaches the adult level at $\sim 6$ mo (Bachevalier et al. 1991). In addition, myelination in this area is not complete until after the age of $1 \mathrm{yr}$ in monkeys (Yakovlev and Lecours 1967). Thus, although inferior temporal cortical areas are functional early after birth, they do not reach full maturity before the end of the first year.

\section{Perirhinal Cortex}

Given the recent emphasis on the role of the perirhinal cortex in visual memory, there are surprisingly few studies exploring the anatomical development of this region. Neurogenesis in these cortical areas (35 and 36) has not been directly examined in the primate. Morphologically, however, development of this area lags behind that of the entorhinal cortex (Berger et al. 1993; Berger and Alvarez 1994). In fact, by the fourth gestational month, the rhinal sulcus is still only a small indent on the cortical surface (Berger and Alvarez 1994). Yet, despite this apparent lag, neurotensin (a pyramidal cell marker, NT) immunoreactive terminals are present in the caudal perirhinal cortex at this time, suggesting that the perirhinal cortex receives extrinsic innervation by the last gestational quarter. Although the source of this input has yet to be determined, CA1 pyramidal cells are possible candidates, as they have been shown to send direct projections to the perirhinal cortex in the adult monkey (Blatt and Rosene 1998), and are NT immunoreactive at this age (Berger and Alvarez 1994). At birth, although the perirhinal cortex can be clearly identified cytoarchitecturally and displays adult-like chemoanatomical characteristics (Berger and Alvarez 1994).

The results of lesion studies suggest that the perirhinal

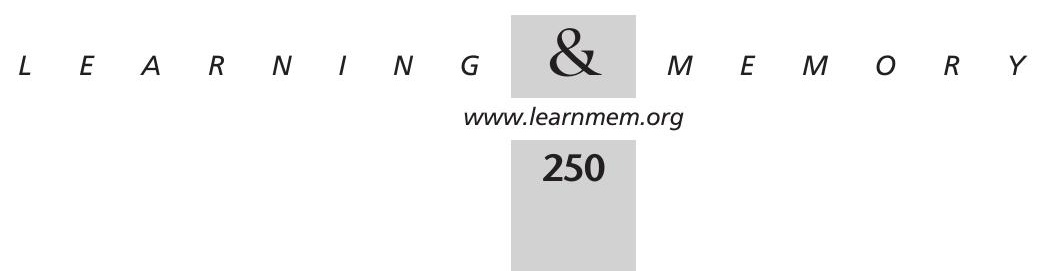


cortex may be functional at birth. In a study examining the effects of early rhinal damage (combined entorhinal and perirhinal removal), it was shown that neonatal damage to the rhinal cortex resulted in equally severe impairments to DNMS as did the same damage sustained in adulthood (Málková et al. 1998). Whereas it is not yet known whether just one or both areas contributed to this effect, the results indicate that the perirhinal cortex may be available to support some memory functions early in life. However, it still undergoes postnatal maturation with respect to the pattern of connections with areas TE and TEO (Webster et al. 1991) and with the ventrolateral portions of the prefrontal cortex (Málková et al., in press). Indeed, based on the immaturity of its cortical inputs, one must conclude that it undergoes functional maturation at least over the first $6 \mathrm{mo}$.

\section{Parahippocampal Area TH/TF}

Neurogenesis in this cortical region has not been directly examined. In the neonate, however, both afferent and efferent connections have been established, although this pattern is immature and is not entirely preserved in the adult (Webster et al. 1991). In addition, the parahippocampal cortex receives its major inputs from cortical areas that have a protracted maturation, such as the parietal cortex which appears to be fully functional by the age of 3 mo (Distler et al. 1996) and the dorsolateral prefrontal cortex which reaches complete maturity around age 2 yr (Alexander and Goldman 1978; Alexander 1982; Goldman et al. 1983). Thus, the data suggest that the parahippocampal cortex shows protracted functional postnatal maturation.

\section{Entorhinal Cortex}

Within the normal monkey gestational period (165 d), cells in the entorhinal cortex are generated beginning on embryonic day 36 (E36), preceding cell generation in the hippocampal formation by $2 \mathrm{~d}$, and continuing to E70 (Rakic and Nowakowski 1981). Cytoarchitectonic analysis revealed that the laminar subdivisions characteristic of the adult entorhinal cortex were identifiable by midgestation with the exception of the lateral entorhinal cortex (that area occupying the medial bank of the rhinal sulcus) which develops fully only in the last quarter of gestation. Innervation of this region is apparent in the second quarter of gestation (Berger et al. 1993, 1999; Berger and Alvarez 1994, 1996). Aminergic innervation of this region appears between E56 and E64. This aminergic innervation increases in density at the end of gestation and shows mature characteristics in the newborn (Berger and Alvarez 1994). The pattern of labeling suggests that at least some of these connections are extrinsic. For example, as for the perirhinal cortex, NT reactive terminals, but not NT reactive neurons, are present in the entorhinal cortex at birth, suggesting the presence of extrinsic innervation at this early age. One possible source of extrinsic innervation originates in the area CA1 of the hip- pocampus proper, which does show NT reactive neurons at this age (Berger et al. 1993).

As discussed for the perirhinal cortex, there is lesion evidence to suggest that the entorhinal cortex could be functional at birth (Málková et al. 1998). However, selective lesion studies are needed to determine the extent to which damage to the entorhinal cortex alone accounts for those results.

\section{Hippocampal Formation}

Neurogenesis in the hippocampus proper begins approximately on E38 and continues through E75 (Nowakowski and Rakic 1981; Rakic and Nowakowski 1981). Genesis of neurons in the dentate gyrus continues throughout gestation and is $\sim 80 \%$ complete at birth, but tapers off between the fourth and 6 postnatal months (Rakic and Nowakowski 1981; Duffy and Rakic 1983; Eckenhoff and Rakic 1988) to a low level that may continue through adult life (Gould et al. 1999; Kornack and Rakic 1999).

Differentiation of the hippocampal cell fields has been shown in rodents and humans to proceed from CA1 to CA3 (Bayer and Altman 1974; Arnold and Trojanowski 1996). Maturation of the CA fields in non-human primates may follow the same pattern. Presently, there are no data describing synaptogenesis in CA1. However, neurons in this region show precocious expression of neurotensin (NT) and may have established connections with the entorhinal cortex by midgestation in monkeys, as suggested by the presence of NT reactive terminals in that region at that stage (Berger et al. 1993, 1994). Indeed, reciprocal connections between CA1 and the entorhinal cortex have been established in the human fetus at $19 \mathrm{wk}$ gestation, at a time when the perforant path projections are sparse (Hevner and Kinney 1996).

Area CA3 has been studied more extensively and shows increases in the maturation rate late in gestation, presumably reflecting increases in mossy fiber afferentation (Seress 1992; Seress and Mrzljak 1992; Seress and Ribak 1995a,b). Furthermore, CA3 pyramidal cells display adultlike ultrastructural features and mature mossy fiber synapses at birth (Vijayan 1986; Seress and Ribak 1995a,b). Nevertheless, they continue to mature postnatally, with increases in size, number, and complexity of adult-like spines on the distal dendrites in the second half of the first postnatal year. Mature mossy fiber synapses are established on most CA3 pyramidal cells at birth, but new synapses are formed throughout the first year (Seress and Ribak 1995a). A similar pattern is observed in the hilar mossy cells, with adult features maturing over the first 3 postnatal months (Seress and Ribak 1995a).

In the dentate gyrus, synaptogenesis begins in the third gestational month and continues throughout gestation (Eckenhoff and Rakic 1991). Synaptic density shows a significant increase in the latter half of gestation and equals that of

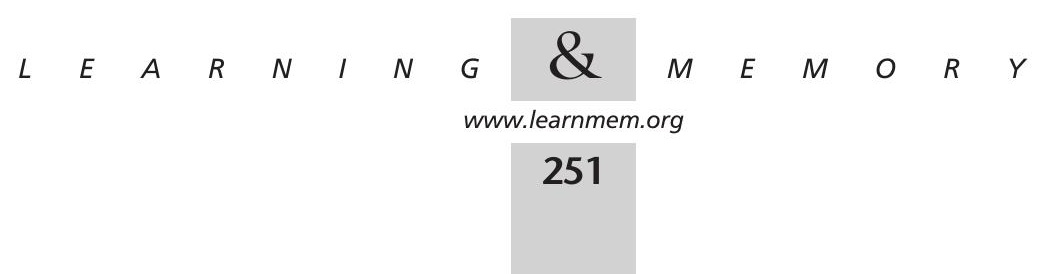


adults at the time of birth. However, whereas prenatal afferents are distributed equally throughout the dentate gyrus, there is a postnatal wave of synaptogenesis restricted to the outer two thirds of the molecular layer (Eckinhoff and Rakic 1991), which corresponds to the terminal zone of entorhinal afferents from layer II of the medial entorhinal cortex (Amaral et al. 1987). This wave peaks at the age of 4-5 mo and is accompanied by a $30 \%$ increase in spine density and asymmetrical synapses as well as a decrease in shaft synapses.

Lastly, myelination of hippocampal afferents and efferents shows substantial postnatal maturation. Whereas there are relatively few myelinated axons in the alveus at birth, approximately one-third of the axons are myelinated in the 3-mo old and 50\% in the 7-mo old (Seress and Ribak 1995a). Myelination of axons in the alveus continues between postnatal months 7 and 9 .

\section{Summary}

The anatomical data show that at birth, the basic pattern of connections between the hippocampal formation and the medial temporal cortical areas has been established, but is neither complete nor fully mature. Indeed, synaptogenesis and myelination in the monkey hippocampal proper and dentate gyrus continue throughout the first postnatal year. Other postnatal events include the addition of new neurons throughout the dentate gyrus, the further refinement of perforant path and mossy fiber projections throughout the first $6 \mathrm{mo}$, and possibly the projections from CA3 to CA1. Within the temporal cortical areas, visual areas TE and TEO show substantial postnatal maturation in terms of metabolic functioning, the retraction of transient connections, and the strengthening and remodeling of permanent connections. In the absence of electrophysiological evidence, it is impossible at this stage to determine when the perirhinal, entorhinal, and parahippocampal cortical areas are functionally mature. It is clear that morphologically, the structures within the medial temporal lobe and their connections continue to show maturational changes across the first $2 \mathrm{yr}$ of life in the monkey.

\section{Maturation of Medial Temporal Lobe Memory Functions}

The behavioral data in rats, monkeys, and humans clearly indicate that the circuit for visual memory is functional at birth in primates and within a day or two of eye-opening in the rat (around day 14), but is neither complete nor mature until approximately the first month in rodents, the second year of life in the monkey, and the fifth year in humans. This suggests that at least some circuitry in the hippocampal region is available early in life, but it is either incomplete or insufficiently mature to support the full range of behavioral functions sensitive to hippocampal damage in adulthood. Thus, the progressive maturation of hippocampal-depen- dent memory functions during development may reflect both the maturation of the functional architecture of the hippocampus proper, the dentate gyrus, and their progressive integrative participation in the cortical circuits that mediate memory. The questions at hand are what might these circuits be, and what do we know about the development of their component structures? Unfortunately, too little is known now to permit specific, detailed answers to these questions. However, given the review of the findings presented above and findings from the rodent literature, one might begin to offer some possible explanations.

As recently discussed by Stanton (2000) for rodents, with respect to hippocampal-dependent tasks such as spatial navigation (Rudy et al. 1987; Altemus and Almli 1997), contextual fear conditioning (Pugh and Rudy 1996), traceeyeblink conditioning (Ivkovich et al. 2000) and spatial delayed alternation (Freeman and Stanton 1991), to name a few, developmental onset is closely tied to completion of neurogenesis of the dentate gyrus. Perhaps more intriguing, however, are the results of studies using non-spatial, hippocampal-sensitive tasks that suggest that the hippocampal formation contributes to earlier developing memory functions as measured, for example, by patterned alternation (Diaz-Granados et al. 1992), or olfactory reversal learning (Saperstein et al. 1989) emerge before complete hippocampal maturation. Conversely, successful performance on tasks such as spatial delayed alternation (Castro et al. 1987) and transverse patterning (J.W. Rudy and M.C. Alvarado, unpubl.) appears some $10 \mathrm{~d}$ to $2 \mathrm{wk}$ after completion of neurogenesis in the dentate gyrus.

Similar to the developmental pattern in the rat, and coincident with the onset of synaptogenesis in the dentate gyrus, infant monkeys increasingly begin to explore their environment, leaving the mother and engaging in social play (Suomi 1984), at the age of $\sim 4$ mo. Weaning also begins at this age and usually continues through months 6 and 7 . This same developmental period in the rat (around postnatal day 21) is also associated with weaning, an increased tendency to leave the nest and explore the environment, and the onset of spatial memory abilities (Rudy et al. 1987). Although the development of spatial memory functions in infant primates remains to be tested, the similarity with ontogenetic events in rodents suggests that the onset of spatial memory abilities in monkeys could occur after the fourth month of life.

In contrast, recognition memory as seen in the preferential looking task early in life could be supported by allocortical areas, such as perirhinal and entorhinal cortex, as well as by the direct circuit originating in layer III of the entorhinal cortex and projecting to CA1 and subiculum. This circuit appears to be present at birth and could support recognition memory early in life as it seems to support it in the adult (Sybirska et al. 2000). Furthermore, given that the inferior temporal cortex, the entorhinal and perirhinal cor-

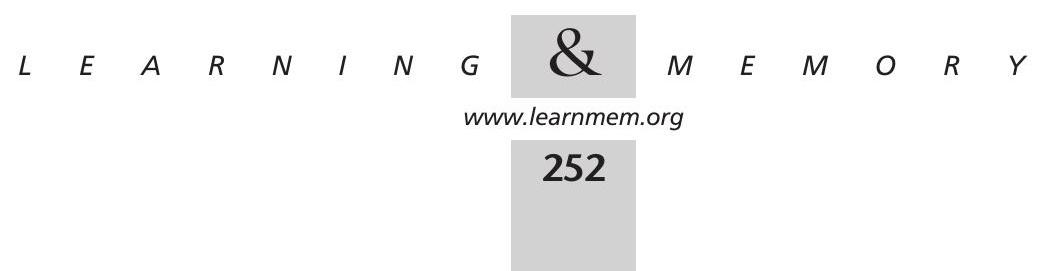


tical regions, and the ventral prefrontal cortex are of particular importance for learning the non-matching principle (Meunier et al. 1993, 1997; Zola-Morgan et al. 1989), further functional maturation within these cortical areas during the first six postnatal months is required to support the emergence of DNMS rule-learning abilities around this age (Bachevalier et al. 1991; Málková et al., in press).

Finally, in monkeys, as in rats, other relational memory abilities seem to postdate the maturation of the trisynaptic circuit that is largely complete by the end of the first year. For example, some infant monkeys could solve the transverse patterning task at the age of $1 \mathrm{yr}$, but few of these were able to reach the adult criterion level of $90 \%$ correct before the age of $3 \mathrm{yr}$ (Málková et al. 1999). Performance of the oddity problem is similarly delayed in monkeys until ages 2-3 yr. These results indicate that the circuitry for performing at least one relational memory task is present by the age of $1 \mathrm{yr}$, but adult performance on the task may require the participation of a fully functional hippocampal formation and its inputs to and from later maturing cortical areas, such as the dorsolateral prefrontal cortex (GoldmanRakic et al. 1984). This portion of the prefrontal cortex is known to have a protracted maturation (Goldman-Rakic 1987; Lewis 1997), and its damage early in life appears to affect performance on the transverse patterning task (Alvarado et al. 1997; M.C. Alvarado, L. Málková, J. Bachevalier, and M. Mishkin, unpubl.) as well as on spatial tasks (Goldman-Rakic 1987).

\section{Conclusions and Perspectives}

We began this review intending to identify that point when the medial temporal lobe is functionally mature. Although there is still much to be learned about specific developmental events, the evidence clearly suggests that this region shows a developmental continuum that directly affects memory abilities throughout ontogeny.

One interesting conclusion that comes from these data is the idea that the hippocampal formation may have several functional modules that contribute differentially to behavior both in infancy and adulthood and which show different rates of maturation. Within the context of multiple memory systems, the general term, hippocampal memory, may be misleading if in fact this structure does not perform the same computation on all incoming information. In other words, it may be possible to dissociate several distinct components within the hippocampal-dependent memory.

This review also suggests important directions for future research. For example, we know very little about the anatomical development of structures such as CA1, perirhinal cortex, and TH/TF. Furthermore, electrophysiological or metabolic studies of all these regions during development will go far toward our understanding of the circuits mediating both infant and adult memory functions. In fact, results from these developmental studies will allow us to draw inferences about the contribution of these structures to behavioral development, and by extension, to memory processes in general.

\section{ACKNOWLEDGMENTS}

This work was supported in part by NRSA grant MH10929 to M.C.A and MH58846 to J.B.

\section{REFERENCES}

Aguirre, G.K., Detre, J.A., Alsop, D.C., and D'Esposito, M. 1996. The parahippocampus subserves topographical learning in man. Cereb. Cortex. 6: 823-829.

Alexander, G.E. 1982. Functional development of frontal association cortex in monkeys: Behavioral and electrophysiological studies. Neurosci. Res. Prog. Bull. 20: 471-479.

Alexander, G.E. and Goldman, P.S. 1978. Functional development of the dorsolateral prefrontal cortex: An analysis utilizing reversible cryogenic depression. Brain Res. 143: 233-249.

Altemus, K.L. and Almli, C.R. 1997. Neonatal hippocampal damage in rats: Long-term spatial memory deficits and associations with magnitude of hippocampal damage. Hippocampus. 7: 403-415

Altman, J., and Bayer, S.A. 1975. Postnatal development of the hippocampal dentate gyrus under normal and experimental conditions. In The Hippocampus (ed. R.L. Isaacson and K.H. Pribram), pp. 95-122. Plenum Press, New York.

Altman, J., Brunner, R.L., and Bayer, S.A. 1973. The hippocampus and behavioral maturation. Behav. Biol. 8: 557-596.

Altman, J. and Das, G.D. 1965. Autoradiographic and histological evidence of postnatal hippocampal neurogenesis in rats. J. Comp. Neurol. 124: 319-336.

Alvarado, M.C. and Rudy, J.W. 1992. Some properties of configural learning: An investigation of the transverse patterning problem. J. Exp. Psychol.: Animal Beh. Proc. 18: 145-153.

- 1995a. A comparison of kainic acid + colchicine and ibotenic acid-induced hippocampal formation damage on four configural tasks. Behav. Neurosci. 109: 1052-1062.

- 1995b. Hippocampal formation damage impairs performance of the transverse patterning problem, but not of concurrent elemental discriminations. Behav. Neurosci. 109: 204-211.

Alvarado, M.C., Wright, A.A., and Bachevalier, J. 1995. Monkeys with early hippocampal formation lesions are impaired on the transverse patterning problem. Soc. Neurosci. Abst. 21: 1494.

Alvarado, M.C., Málková, L., Lex, C.K., Mishkin, M., and Bachevalier, J. 1997. Effects of early lesions of the inferior convexity and orbital prefrontal cortices on relational memory in rhesus monkeys. Soc. Neurosci. Abst. 23: 498 .

Alvarado, M.C., Mishkin, M., and Bachevalier, J. 1998. Neurotoxic lesions of the hippocampal formation impair monkeys' acquisition of the transverse patterning problem. Soc. Neurosci. Abst. 24: 928.

Alvarez, P., Zola-Morgan, S., and Squire, L.R. 1995. Damage limited to the hippocampal region produces long-lasting memory impairment in monkeys. J. Neurosci. 15: 3796-3807.

Amaral, D.G., Insausti, R., and Cowan, W.M. 1987. The entorhinal cortex of the monkey: I. Cytoarchitectonic organization. J. Comp. Neurol. 264: 326-355

Arnold, S.E. and Trojanowski, J.Q. 1996. Human fetal hippocampal development: II. The neuronal cytoskeleton. J. Comp. Neurol. 367: 293-307.

Bachevalier, J. 1990. Ontogenetic development of habit and memory formation in primates. Ann. N.Y. Acad. Sci. 608: 457-477.

Bachevalier, J. and Mishkin, M. 1984. An early and late developing systems for learning and retention in infant monkeys. Behav. Neurosci. 98: $770-778$.

Bachevalier, J. and Beauregard, M. 1993. Maturation of medial temporal lobe memory functions in rodents, monkeys, and humans. Hippocampus. 3: 191-202.

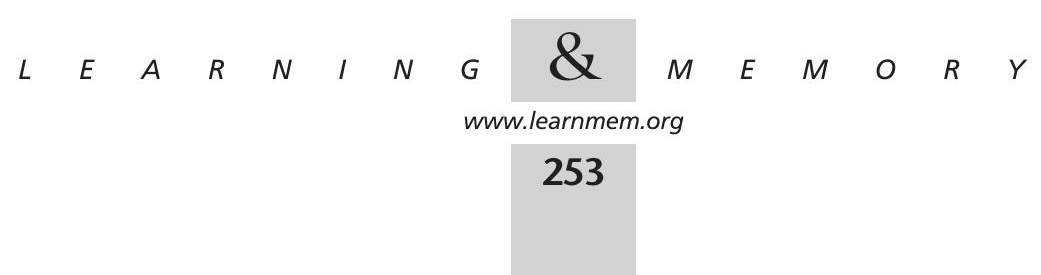


Bachevalier, J. and Mishkin, M. 1994. Effects of selective neonatal temporal lobe lesions on visual recognition memory in rhesus monkeys. $J$. Neurosci. 14: 2128-2139.

Bachevalier, J., Hagger, C., and Bercu, B.B. 1989. Gender differences in visual habit formation in 3-mo-old rhesus monkeys. Dev. Psychobio. 22: 585-599.

Bachevalier, J., Brickson, M., Hagger, C., and Mishkin, M. 1990. Age and sex differences in the effects of selective temporal lobe lesion on the formation of visual discrimination habits in rhesus monkeys. Behav. Neurosci. 104: 885-899.

Bachevalier, J., Hagger, C., and Mishkin, M. 1991. Functional maturation of the occipitotemporal pathway in infant rhesus monkeys. In Alfred Benzon symposium no. 31: Brain work and mental activity, quantitative studies with radioactive tracers (ed. N.A. Lassen, D.H Ingvar, M.E. Raichle, and L. Friberg), pp. 231-240. Munksgaard, Copenhagen.

Bachevalier, J., Brickson, M., and Hagger, C. 1993. Limbic-dependent recognition memory in monkeys develops early in infancy. Neuroreport. 4: 77-80.

Bachevalier, J., Beauregard, M., and Alvarado, M.C. 1999. Long-term effects of neonatal damage to the hippocampal formation and amygdaloid complex on object discrimination and object recognition in rhesus macaques. Beh. Neurosci. 113: 1127-1151.

Bayer, S.A. 1980. Development of the hippocampal region in the rat. I. Neurogenesis examined with $3 \mathrm{H}$-thymidine autoradiography. J. Comp. Neurol. 190: 87-114

Bayer, S.A. and Altman, J. 1974. Hippocampal development in the rat: Cytogenesis and morphogenesis examined with autoradiography and low-level x-radiation. J. Comp. Neurol. 158: 55-80.

Baylis, G.C., Rolls, E.T., and Leonard, C.M. 1987. Functional subdivisions of the temporal lobe neocortex. J. Neurosci. 7: 330-342.

Beason-Held, L.L., Rosene, D.L., Killiany, R.J., and Moss, M.B. 2000. Hippocampal formation lesions produce memory impairment in the rhesus monkey. Hippocampus. 9: 562-74.

Berger, B. and Alvarez, C. 1994. Neurochemical development of the hippocampal region in the fetal rhesus monkey. II. Immunocytochemistry of peptides, calcium-binding proteins, DARPP-32, and monoamine innervation in the entorhinal cortex by the end of gestation. Hippocampus. 4: 84-114.

- 1996. Neurochemical development of the hippocampal region in the fetal rhesus monkey. III: Calbindin-D28K, calretinin and parvalbumin with special mention of cajal-retzius cells and the retrosplenial cortex. J. Comp. Neurol. 366: 674-699.

Berger, B., Alvarez, C., and Goldman-Rakic, P.S. 1993. Neurochemical development of the hippocampal region in the fetal rhesus monkey. I. Early appearance of peptides, calcium-binding proteins, DARPP-32, and the nmonoamine innervation in the entorhinal cortex during the first half of gestation (E47 to 90). Hippocampus. 3: 279-305.

Berger, B., de Grissac, N., and Alvarez, C. 1999. Precocious development of parvalbumin-like immunoreactive interneurons in the hippocampal formation and entorhinal cortex of the fetal cynomolgus monkey. $J$. Comp. Neurol. 403: 309-331.

Blatt, G.J. and Rosene, D.L. 1998. Organization of direct hippocampal efferent projections to the cerebral cortex of the rhisus monkey: Projections from CA1, prosubiculum, and subiculum to the temporal lobe. J. Comp. Neurol. 392: 92-114.

Brown, M.W. 1996. Neuronal responses and recognition memory. Seminars in the Neurosciences. 8: 23-32.

Buffalo, E.A., Ramus, S.J., Clark, R.E., Teng, E., Squire, L.R., and Zola, S.M. 1999. Dissociation between the effects of damage to perirhinal cortex and area TE. Learn. Mem. 6: 572-599.

Castro, C.A., Paylor, R., and Rudy, J.W. 1987. A developmental analysis of the learning and short-term-memory processes mediating performance in conditional-spatial discrimination problems. Psychobiology. 15: $308-316$

Clark, R.E., Teng, E., Squire, L.R., and Zola, S. 1996. The visual paired-comparison task and the medial temporal lobe memory system. Soc. Neurosci. Abstr. 22: 281.
Colombo, M. and Gross, C.G. 1994. Responses of inferior temporal cortex and hippocampal neurons during delayed matching to sample in monkeys (Macaca fascicularis). Behav. Neurosci. 108: 443-455.

Colombo, M., Fernandez, T., Nakamura, K., and Gross, C.G. 1998. Functional differentiation along the anterior-posterior axis of the hippocampus in monkeys. J. Neurophysiol. 80: 1002-1005.

Deadwyler, S.A., Bunn, T., and Hampson, R.E. 1996. Hippocampal ensemble activity during spatial delayed-nonmatch-to-sample performance in rats. J. Neurosci. 16: 354-372.

Desimone, R. 1992. The physiology of memory: Recordings of things past. Science. 258: 245-246.

Desimone, R. and Ungerleider, L.G. 1989. Neural mechanisms of visual processing in monkeys. In Handbook of Neuropsychology (ed. F. Boller and J. Grafman), pp. 267-299. Elsevier Science Publishers, City.

Diamond, A. 1990. Rate of maturation of the hippocampus and the developmental progression of children's performance on the delayed nonmatching-to-sample and visual paired comparison tasks. Ann. N.Y. Acad. Sci. 608: 394-426.

- 1995. Evidence of robust recognition memory early in life even when assessed by reaching behavior. J. Exp. Child Psychol. 59: 419-456.

Diamond, A., Churchland, A., Cruess, L., and Kirkham, N.Z. 1999. Early developments in the ability to understand the relation between stimulus and reward. Dev. Psychol. 35: 1507-1517.

Diaz-Granados, J.L., Greene, P.L., and Amsel, A. 1992. Selective activity enhancement and persistence in weanling rats after hippocampal $\mathrm{X}$-irradiation in infancy: Possible relevance for ADHD. Behav. Neural Bio. 61: 251-259.

Distler, C., Bachevalier, J., Kennedy, C., Mishkin, M., and Ungerleider, L.G. 1996. Functional development of the corticocortical pathway for motion analysis in the macaque monkey: A 14C-2-deoxyglucose study. Cerebral Cortex. 6: 184-195.

Douglas, R.J. 1975.The development of hippocampal function: Implications for theory and for therapy. In The Hippocampus (ed. R.L. Isaacson and K.H. Pribram), pp. 327-361. Plenum Press, New York.

Duffy, C.J. and Rakic, P. 1983. Differentiation of granule cell dendrites in the dentate gyrus of the rhesus monkey: A quantitative Golgi study. $J$. Comp. Neurol. 214: 224-237.

Eacott, M.J., Gaffan, D., and Murray, E.A. 1994. Preserved recognition memory for small sets, and impaired stimulus identification for large sets, following rhinal cortex ablations in monkeys. Eur. J. Neurosci. 6: $1466-1478$

Eckenhoff, M.F. and Rakic, P. 1988. Nature and fate of proliferative cells in the hippocampal dentate gyrus during the life span of the rhesus monkey. J. Neurosci. (8): 2729-2747.

. 1991. A quantitative analysis of synaptogenesis in the molecular layer of the dentate gyrus in the rhesus monkey. Dev. Brain Res. 64: $129-136$.

Fagan, J.F. III. 1970. Memory in the infant. J. Exp. Child Psychol. 9: $217-226$.

Fahy, F.L., Riches, I.P., and Brown, M.W. 1993. Neuronal activity related to visual recognition memory: Long-term memory and the encoding of recency and familiarity information in the primate anterior and medial inferior temporal and rhinal cortex. Exp. Brain Res. 96: 457-472.

Fantz, R.L. 1964. Visual experience in infants: Decreaased attention to familiar patterns relative to novel ones. Science. 146: 668-670.

Freeman, J.H. and Stanton, M.E. 1991. Fimbria-fornix transections disrupt the ontogeny of delayed alternation but not position discrimination in the rat. Behav. Neurosci. 105: 386-395.

George, P.J., Horel, J.A., and Cirillo, R.A. 1989. Reversible cold lesions of the parahippocampal gyrus in monkeys results in deficits of the delayed matching-to-sample and other visual tasks. Behav. Brain Res. 34: 163-178.

Goldman-Rakic, P.S. 1987. Cellular and circuit basis of working memory in prefrontal cortex of nonhuman primates. Prog. Brain Res. 85: $325-336$

Goldman-Rakic, P.S., Isseroff, A., Schwartz, M.L., and Bugbee, N.M. 1983. The neurobiology of cognitive development. In Handbook of child

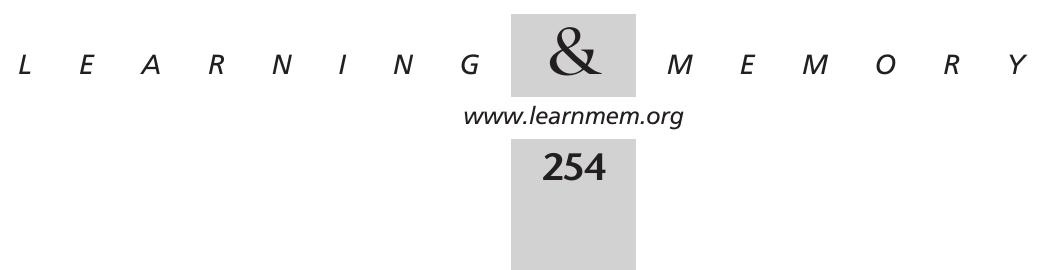


psychology: Biology and infancy development (ed. P. Mussen) Vol. 2., pp. 281-344. Wiley, New York

Goldman-Rakic, P.S., Selemon, L.D., and Schwartz, M.L. 1984. Dual pathways connecting the dorsolateral prefrontal cortex with the hippocampal formation and parahippocampal cortex in the rhesus monkey. Neurosci. 12: 719-743.

Gollin, E.S. and Schadler, M. 1972. Relational learning and transfer by young children. J. Exp. Child Psychol. 14: 219-232.

Gould, E., Reeves, A.J., Fallah, M., Tanapat, P., Gross, C.G., and Fuchs, E. 1999. Hippocampal neurogenesis in adult Old World primates. Proc. Natl. Acad. Sci. U.S.A. 96: 5263-5267.

Gunderson, V.M. and Sackett, G.P. 1984. Development of pattern recognition in infant pigtailed macaques (Macaca nemestrina). Develop. Psychol. 20: 418-426.

Gunderson, V.M. and Swartz, K.B. 1985. Visual recognition in infant pigtailed macaques after 24-h delay. Am. J. Primat. 8: 259-264.

Hampson, R.E., Heyser, C.J., and Deadwyler, S.A. 1993. Hippocampal cell firing correlates of delayed-match-to-sample performance in the rat. Behav. Neurosci. 107: 715-739.

Harlow, H. (1959). The development of learning in the rhesus monkey. Am. Scientist. Winter: 459-479.

Hevner, R.F. and Kinney, H.C. 1996. Reciprocal entorhinal-hippocampal connections established by human fetal midgestation. J. Comp. Neurol. 372: 384-394

Horel, J.A., Pytko-Joyner, D.E., Voytko, M.L., and Salsbury, K. 1987. The performance of visual tasks while segments of the inferotemporal cortex are suppressed by cold. Beh. Brain Res. 23: 29-42.

Insausti, R., Amaral, D.G., and Cowan, W.M. 1987. The entorhinal cortex of the monkey II. Cortical afferents. J. Comp. Neurol. 264: 356-395.

Iversen, S.D. and Humphrey, N.K. 1971. Ventral temporal lobe lesions and visual oddity performance. Brain Res. 30: 253-263.

Ivkovich, D., Paczkowski, C.M., and Stanton, M.E. 2000. Ontogeny of delay versus trace eyeblink conditioning the rat. Dev. Psychobiol. 35: 253-263.

Killiany, R. and Mahut, H. 1990. Hippocampectomy in infant monkeys facilitates object reward association learning but not for conditional object-object associations. Soc. Neurosci. Abstr. 16: 847.

Kornack, D.R. and Rakic, P. 1999. Continuation of neurogenesis in the hippocampus of the adult macaque monkey. Proc. Natl. Acad. Sci. 96: 5768-5773.

Lewis, D.A. 1997. Development of the primate prefrontal cortex. In Neurodevelopment and adult psychopathology (ed. M.S. Keshavan and R.M. Murray), pp. 12-30. Cambridge University Press, New York.

Lobaugh, N.L., Bootin, M., and Amsel, A. 1985. Sparing of patterned alternation but not partial reinforcement effect after infant and adult hippocampal lesions in rat. Behav. Neurosci. 99: 46-59.

Mahut, H. and Moss, M. 1986. The monkey and the seahorse. In The Hippocampus (ed. R.L. Isaacson and K.H. Pribram), pp. 241-279. Plenum Press, New York

Mahut, H. and Killiany, R. 1990. Ontogeny of object-reward association learning and trial-unique object recognition memory: Effects of early hippocampectomy on the two capcities in rhesus macaques. Soc. Neurosci. Abstr. 16: 847.

Málková, L., Mishkin, M., and Bachevalier, J. 1995. Long-term effects of selective neonatal temporal lobe lesions on learning and memory in monkeys. Behav. Neurosci. 109: 212-226.

Málková, L., Pixley, E., Webster, M.J., Mishkin, M., and Bachevalier, J. 1998. The effects of early rhinal lesions on visual recognition memory in rhesus monkeys. Soc. Neurosci. Abst. 18: 957.

Málková, L., Alvarado, M.C., Pixley, E.L., Belcher, A.M., Mishkin, M., and Bachevalier, J. 1999. Maturation of relational memory processes in monkeys. Soc. Neurosci. Abstr. 25: 1892.

Málková, L., Bachevalier, J., Webster, M.J., and Mishkin, M. In press. Effects of neonatal inferior prefrontal and medial temporal lesions on learning the rule for delayed nonmatching-to-sample. Dev. Neuropsych.

Matsumura, N., Nishijo, H., Tamura, R., Eifuku, S., Endo, S., and Ono, T. 1999. Spatial-and task-dependent neuronal responses during real and virtual translocation in the monkey hippocampal formation. $J$. Neurosci. 19: 2381-2393.

Meunier, M., Bachevalier, J., Mishkin, M., and Murray, E.A. 1993. Effects on visual recognition of combined and separate ablations of the entorhinal and perirhinal cortex in rhesus monkeys. J. Neurosci. 13: 5418-5432.

Meunier, M., Bachevalier, J., and Mishkin, M. 1997. Effects of orbital frontal and anterior cingulate lesions on object and spatial memory in rhesus monkeys. Neuropsychologia. 35: 999-1015.

Miller, E.K. and Desimone, R. 1994. Parellel neuronal mechanisms for short-term memory. Science. 263: 520-522.

Miller, E.K., Li, L., and Desimone, R. 1991. A neural mechanism for working and recognition memory in inferior temporal cortex. Science. 254: $1377-1379$.

-1993. Activity of neurons in anterior inferior temporal cortex during a short-term memory task. J. Neurosci. 13: 1460-1478.

Mishkin, M. and Murray, E.A. 1996. Stimulus recognition. Curr. Opin. Neurobiol. 4: 200-206.

Mishkin, M., Vargha-Khadem, F., and Gadian, D.G. 1998. Amnesia and the organization of the hippocampal system. Hippocampus. 8: 212-216

Morris, R.G.M., Garrud, P., Rawlins, J.N., and O'Keefe, J. 1982. Place navigation impaired in rats with hippocampal lesions. Nature. 297: 681-683

Moser, M-B. and Moser, E.I. 1998. Functional differentiation in the hippocampus. Hippocampus. 8: 608-619.

Murray, E.A. 1992. Medial temporal lobe structures contributing to recognition memory: The amygdaloid complex versus the rhinal cortex. In The Amygdala: Neurobiological Aspects of Emotion, Memory, and Mental Dysfunction (ed. J.P. Aggleton), pp. 453-470. Wiley, New York.

Nemanic, S., Alvarado, M.C., and Bachevalier, J. 1998. Differential effects of selective hippocampal lesions on two visual recognition tasks in monkeys. Cog. Neurosci. Soc. Abst. 121.

- 1999. Effects of interference on DNMS performance after selective hippocampal lesions in monkeys. Soc. Neurosc. Abst. 25: 88.

- 2000. Effects of lesions of the parahippocampal gyrus (TH/TF) on two tasks of object recognition memory in monkeys. Soc. Neurosci. Abst. In press.

Nowakowski, R.S. and Rakic, P. 1981. The site of origin and route and rate of migration of neurons to the hippocampal region of the rhesus monkey. J. Comp. Neurol. 196: 129-154.

Overman, W.H. 1990. Performance on traditional match-to-sample, non-match-to-sample, and object discrimination task by 12- to 32-mo-old children: A developmental progression. Ann. N.Y. Acad. Sci. 608: $365-383$.

Overman, W.H., Bachevalier, J., Sewell, F., and Drew, J. 1993. A comparison of children's performance on two recognition memory tasks: Delayed nonmatch-to-sample versus visual paired-comparison. Dev. Psychobiol. 26: 345-357.

Overman, W.H., Pate, B.J., Moore, K., and Peuster, A. 1996. Ontogeny of place learning in children as measured in the radial arm maze, Morris search task, and open field task. Behav. Neurosci. 110: 1205-1228.

Pascalis, O. and de Schonen, S. 1994. Recognition memory in 3-4 day-old human infants. Neuroreport. 5: 1721-1724.

Pascalis, O. and Bachevalier, J. 1999. Neonatal aspiration lesions of the hippocampal formation impair visual recognition memory when assessed by paired-comparison task but not by delayed nonmatching-to-sample task. Hippocampus. 9: 609-616

Pugh, C.R. and Rudy, J.W. 1996. A developmental analysis of contextual fear conditioning. Dev. Psychobiol. 29: 87-100.

Rakic, P. and Nowakowski, R.S. 1981. The time of origin of neurons in the hippocampal region of the rhesus monkey. J. Comp. Neurol. 196: 99-128.

Reed, J.M. and Squire, L.R. 1999. Impaired transverse patterning in human amnesia is a special case of impaired memory for two-choice discrimination tasks. Behav. Neurosci. 113: 3-9.

Rickard, T.C. and Grafman, J. 1998. Losing their configural mind. Amnesic patients fail on transverse patterning. J. Cog. Neurosci. 10: 509-524.

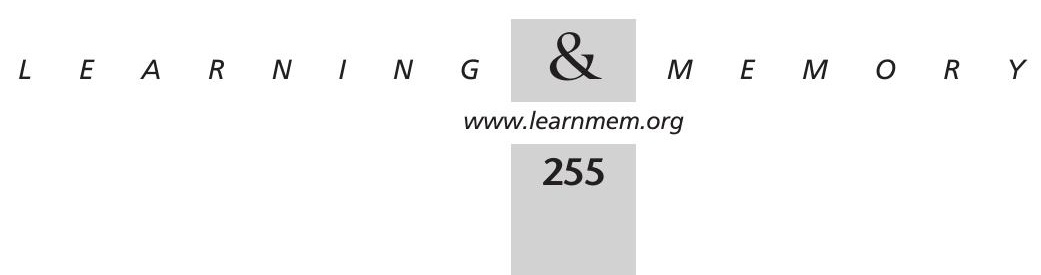


Riches, I.P., Wilson, F.A., and Brown, M.W. 1991. The effects of visual stimulation and memory on neurons of the hippocampal formation and the neighboring parahippocampal gyrus and inferior temporal cortex of the primate. J. Neurosci. 11: 1763-1779.

Robertson, R.G., Rolls, E.T., Georges-Francois, P., and Panzeri, S. 1999 Head direction cells in the primate pre-subiculum. Hippocampus. 9: 206-219.

Rodman, H.R. 1994. Development of inferior temporal cortex in the monkey. Cerebr. Cortex. 5: 484-498.

Rodman, H.R., O'Scalaidhe, S.P., and Gross, C.G. 1993. Visual response properties of neurons in temporal cortical visual areas of infant monkeys. J. Neurophys. 70: 1115-1136.

Rolls, E.T., Robertson, R.G., and Georges-Francois, P. 1997. Spatial view cells in the primate hippocampus. Eur. J. Neurosci. 9: 1789-1794.

Rudy, J.W. 1992. Development of learning: From elemental to configural associative networks. In Advances in infancy research (ed. C. Rovee-Collier and L.P. Lipsit), pp. 247-289. ABLEX Publishing, City.

Rudy, J.W., Stadler-Morris, S., and Albert, P. 1987. Ontogeny of spatial navigation behaviors in the rat: Dissociation of "proximal-" and "distal-" cue-based behaviors. Behav. Neurosci. 101: 732-734.

Rudy, J.W., Keith, J., and Georgian, K. 1993. The effect of age on children's learning of problems that require a configural association solution. Dev. Psychobiol. 26: 171-184.

Saunders, R.C. and Weiskrantz, L. 1989. The effects of fornix transection and combined fornix transection, mamillary body lesions and hippocampal ablations on object-paired association memory in the rhesus monkey. Beh. Brain Res. 35: 85-89.

Saperstein, L.A., Kucharski, D., Stanton, M.E., and Hall, W.G. 1989. Developmental change in reversal learning of an olfactory discrimination. Psychobiology. 17: 293-299.

Seress, L. 1992. Morphological variability and developmental aspects of monkey and human granule cells: Differences between the rodent and primate dentate gyrus. In The dentate gyrus and its role in seizures (ed. C.E. Ribak, C.M. Gall, and I. Mody), pp. 3-28. Elsevier, Amsterdam.

Seress, L. and Mrzljak, L. 1992. Postnatal development of mossy cells in the human dentate gyrus: A light microscopic study. Hippocampus. 2: 127-142.

Seress, L. and Ribak, C.E. 1995a. Postnatal development of CA3 pyramidal neurons and their afferents in the ammon's horn of rhesus monkeys. Hippocampus. 5: 217-231.

1995b. Postnatal development and synaptic connections of hilar mossy cells in the hippocampal dentate gyrus of rhesus monkeys. $J$. Comp. Neurol. 355: 93-110.

Spence, K.W. 1952. The nature of response in discrimination learning Psychol. Rev. 59: 89-93.

Saleem, K.S. and Tanaka, K. 1996. Divergent projections from the anterior inferotemporal area TE to the perirhinal and entorhinal cortices in the macaque monkey. J. Neurosci. 16: 4757-4775.

Squire, L.R. 1994. Declarative and nondeclarative memory: Multiple brain systems supporting learning and memory. In Memory Systems 1994 (ed. D.L. Schacter and E. Tulving), pp. 203-231. MIT Press, Cambridge.

Stanton, M. 2000. Multiple memory systems, development and conditioning. Beh. Brain Res. 110: 25-37.

Suomi, S. 1984. The development of affect in rhesus monkeys. In The psychobiology of affective development (ed. N.A. Fox and R.J. Davidson), pp.119-159. Lawrence Erlbaum Associates,.

Suzuki, W.A. 1996. The anatomy, physiology and functions of the perirhinal cortex. Curr. Opin. Neurobiol. 6: 179-186.

Suzuki, W.A. and Amaral, D.G. 1994a. Topographic organization of the reciprocal connections between the monkey entorhinal cortex and the perirhinal and parahippocampal cortices. J. Neurosci. 14: 1856-1877.

. 1994b. Perirhinal and parahippocampal cortices of the macaque monkey: Cortical afferents. J. Comp. Neurol. 350: 497-533.

Suzuki, W.A., Zola-Morgan, S., Squire, L.R., and Amaral, D.G. 1993. Lesions of the perirhinal and parahippocampal cortices in the monkey produce long-lasting memory impairment in the visual and tactual modalities. J. Neurosci. 13: 2430-2451.

Sybirska, E., Davachi, L., and Goldman-Rakic, P.S. 2000. Prominence of direct entorhinal-CA1 pathway activation in sensorimotor and cognitive tasks revealed by 2-DG functional mapping in nonhuman primates. J. Neurosci. 20: 5827-5834.

Ungerleider, L.G. and Mishkin, M. 1982. Two cortical visual systems. In Analysis of Visual Behavior (ed. D.J. Ingle, M.A. Goodale, and R.J.W Mansfield), pp. 549-586. MIT Press, Cambridge.

Van Hoesen, G.W. 1980. The cortico-cortical projections of the posterior parahippocampal area in the rhesus monkey. Anat. Rec. 196: 195A.

Van Hoesen, G.W. and Pandya, D. 1975. Some connections of the entorhinal (area 28) and perirhinal (area 35) cortices of the rhesus monkey. I. Temporal lobe afferents. Brain Res. 95: 1-24.

Van Hoesen, G., Pandya, D.N., and Butters, N. 1975. Some connections of the entorhinal (area 28) and perirhinal (area 35) cortices of the rhesus monkey. II. Frontal lobe afferents. Brain Res. 95: 25-38.

Vijayan, V.K. 1986. Morphogenesis of the mossy fiber synapses in the hippocampus of the rhesus monkey. Brain Res. 390: 259-270.

Webster, M.J., Ungerleider, L.G., and Bachevalier, J. 1991. Connections of inferior temporal areas TE and TEO with medial -temporal lobe structures in infant and adult monkeys. J. Neurosci. 11: 1095-1116. . 1995. Development and plasticity of the neural circuitry underlying visual recognition memory. Can. J. Physiol. Pharmacol. 73: $1364-1371$.

Witter, M.P. and Amaral, D.G. 1991. Entorhinal cortex in the monkey. V. Projections to the dentate gyrus, hippocampus, and subicular complex. J. Comp. Neurol. 307: 437-459.

Witter, M.P., Van Hoesen, G.W., and Amaral, D.G. 1989. Topographical organization of the entorhinal projection to the dentate gyrus of the monkey. J. Neurosci. 9: 216-228.

Wood, E.R., Dudchenko, P.A., and Eichenbaum, H. 1999. The global record of memory in hippocampal neuronal activity. Nature. 397: 613-616

Xiang, J.-Z. and Brown, M.W. 1998. Differential neuronal encoding of novelty, familiarity and recency in regions of the anterior temporal lobe. Neuropharmacol. 37: 657-676.

Yakovlev, P.I. and Lecours, A.-R. 1967. The myelogenetic cycles of regional maturation of the brain. In Regional development of the brain in early life (ed. A. Minkowski), pp. 3-70. Blackwell, Oxford

Yeckel, M.F. and Berger, T.W. 1990. Feedforward excitation of the hippocampus by afferents from the entorhinal cortex: redefinition of the role of the trisynaptic pathway. Proc. Natl. Acad. Sci. 87:

Zola-Morgan, S., Squire, L.R., Amaral, D.G., and Suzuki, W.A. 1989. Lesions of perirhinal and parahippocampal cortex that spare the amygdala and hippocampal formation produce severe memory impairment. $J$. Neurosci. 9: 4355-4370.

Zola-Morgan, S., Squire, L.R., Clower, R.P., and Rempel, N.L. 1993. Damage to the perirhinal cortex exacerbates memory impairment following lesions to the hippocampal formation. J. Neurosci. 13: 251-265.

Zola, S.M, Squire, L.R., Teng, E., Stefanacci, L., Buffalo, E.A., and Clark, R.E. 2000. Impaired recognition memory in monkeys after damage limited to the hippocampal region. J. Neurosci. 20: 451-463. 


\section{Erratum}

Learning \& Memory 7: 244-256 (2000)

Revisiting the Maturation of Medial Temporal Lobe Memory Functions in Primates

Maria C. Alvarado and Jocelyn Bachevalier

The introductory paragraph of the text of this paper was inadvertently set as an abstract by the publisher.

In Table 1 (p. 247) the publication date of Clark et al. is 1996, not 1997; the publication date of Buffalo et al. is 1999, not 1998.

LEARNING \& MEMORY 7:453 @ 2000 by Cold Spring Harbor Laboratory Press ISSN1072-0502/00 \$5.00

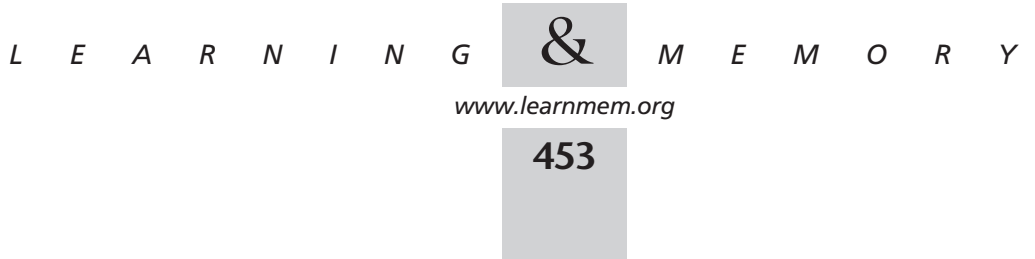




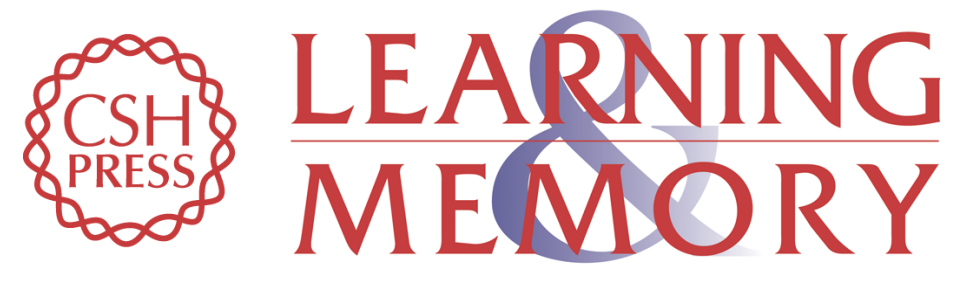

\section{Revisiting the Maturation of Medial Temporal Lobe Memory Functions in Primates}

Maria C. Alvarado and Jocelyne Bachevalier

Learn. Mem. 2000, 7:

Access the most recent version at doi:10.1101//m.35100

Related Content Errata for vol. 7, p. 244

Learn. Mem. November , 2000 7: 453

References This article cites 118 articles, 24 of which can be accessed free at: http://learnmem.cshlp.org/content/7/5/244.full.htmI\#ref-list-1

Articles cited in:

http://learnmem.cshlp.org/content/7/5/244.full.html\#related-urls

License

Email Alerting Receive free email alerts when new articles cite this article - sign up in the box at the Service top right corner of the article or click here. 